\title{
Comparison of Diagnostic Sensitivities for Resectable Pancreatic Adenocarcinoma Between Endoscopic Ultrasound-guided Fine-needle Aspiration and Blinded Computed Tomography
}

\author{
Daisuke Ito ${ }^{1^{*}}$, Yoshikuni Kawaguchi ${ }^{{ }^{*}}$, Naoki Okura ${ }^{2}$, Junichi Arita ${ }^{1}$, Tsuyoshi Hamada ${ }^{3}$, Yousuke Nakai ${ }^{3}$, \\ Hiroyuki Isayama ${ }^{3}$, Nobuhisa Akamatsu ${ }^{1}$, Junichi Kaneko ${ }^{1}$, Yoshihiro Sakamoto ${ }^{1}$, Kazuhiko Koike ${ }^{3}$, \\ Norihiro Kokudo ${ }^{1}$, Kiyoshi Hasegawa ${ }^{1}$
}

\author{
Corresponding author: \\ Kiyoshi Hasegawa, M.D., Ph.D. \\ Hepato-Biliary-Pancreatic Surgery \\ Division, Department of Surgery, \\ Graduate School of Medicine, \\ The University of Tokyo \\ 7-3-1 Hongo, Bunkyo-ku, Tokyo \\ 113-8655, Japan \\ Tel: $+81-3-5800-8841$ \\ Fax: +81-3-5800-8843 \\ E-mail: kihase-tky@umin.ac.jp \\ *Both authors Daisuke Ito, M.D. and \\ Yoshikuni Kawaguchi, M.D., Ph.D. \\ contributed equally.
}

${ }^{1}$ Hepato-Biliary-Pancreatic Surgery Division, Department of Surgery, Graduate School of Medicine, the University of Tokyo, Japan

${ }^{2}$ Department of Radiology, Graduate School of Medicine, the University of Tokyo, Japan ${ }^{3}$ Department of Gastroenterology, Graduate School of Medicine, the University of Tokyo, Japan

\section{ABSTRACT}

Background: Endoscopic ultrasound-guided fine-needle aspiration (EUS-FNA) is performed for diagnosing pancreatic lesions. As EUS-FNA can develop needle track seeding, its use for radiographically-diagnosed pancreatic malignancy remains controversial. We investigated a useful setting of EUS-FNA for resectable pancreatic adenocarcinoma by comparing the diagnostic sensitivity between EUS-FNA and contrast enhanced-computed tomography (CT), and by evaluating the short- and long-term outcomes.

Methods: Between January 2012 and March 2015, 107 consecutive patients underwent resection for pancreatic adenocarcinoma were evaluated retrospectively. Short- and longterm outcomes were compared between patients receiving EUS-FNA and patients who did not.

Results: EUS-FNA was performed for 52 patients (48.6\%).Diagnostic sensitivity of EUS-FNA $(90.4 \%)$ was significantly higher than for blinded $\mathrm{CT}(69.2 \%)(p=0.021)$. EUS-FNA accurately diagnosed pancreatic adenocarcinoma in 16 of $16(100 \%)$ patients who had small tumor diameter, autoimmune pancreatitis, or IPMN-related tumor although they were not correctly diagnosed by radiographic findings. In particular, the sensitivity of EUS-FNA was approximately $90 \%$, irrespective of tumor size, while that for blinded CT was low in cases with a small tumor size (46\% for TS1 tumor). Preoperative EUS-FNA was not associated with overall survival $(p=0.958)$, recurrence-free survival $(p=0.357)$, and relapse rate at peripancreatic tissue and/or peritoneum $(p=0.641)$.

Conclusion: EUS-FNA is particularly useful for diagnosing small pancreatic ductal adenocarcinoma, adenocarcinoma with pancreatitis or IPMN-related adenocarcinoma, providing high diagnostic sensitivity and acceptable prognostic outcomes.

Abbreviations: AC, adjuvant chemotherapy; ASA, American Society of Aesthesiologists; CA19-9, carbohydrate antigen 19-9; CE, contrast enhanced, $\mathrm{CEA}$, carcinoembryonic antigen; $\mathrm{Cl}$, confidence interval; CT, computed tomography; DUPAN-2, duke pancreatic monoclonal antigen type
2; EUS, endoscopic ultrasound; FNA, fine-needle aspiration; HR, hazard ratio; IPMC, intrapapillary mucinous carcinoma; OS, overall survival; RFS, recurrence-free survival; Span-1, s-pancreas-1 antigen; TS, tumor size; UICC, International Union Against Cancer.

Key word: Endoscopic ultrasound fine-needle aspiration, Pancreatic adenocarcinoma, Peritoneal dissemination 


\section{INTRODUCTION}

Pancreatic cancer is the fourth leading cause of cancer-related death in Europe and the United States, and the fourth leading cause in Japan (1-3). Surgical resection is the gold standard for treatment of resectable pancreatic adenocarcinoma, and provides a longer survival period than non-surgical treatments (1). Recently, endoscopic ultrasound-guided fine-needle aspiration (EUS-FNA) was applied for preoperative histological diagnosis, with a reliable diagnostic value including high sensitivity and specificity $(4,5)$. However, previously reported complications of EUS-FNA, (6-8) especially needle track seeding, (9-15) may limit the oncological outcomes of pancreatic adenocarcinoma when it is resectable. Thus, the application of EUS-FNA for resectable pancreatic adenocarcinomain clinical practice remains controversial.

Computed tomography (CT) and magnetic resonance imaging (MRI) with contrast enhancement are used for diagnosing pancreatic lesions. However, it remains unknown whether the diagnostic sensitivity for resectable pancreatic adenocarcinoma of EUS-FNA are different from those of radiographic techniques.

To address these gaps, we evaluated the short- and long-term outcomes in patients who underwent preoperative EUS-FNA for resectable pancreatic adenocarcinoma and the difference of diagnostic sensitivity between EUS-FNA and cross sectional imaging.

\section{PATIENTS AND METHODS}

\section{Patients}

Between January 2012 and March 2015, 160 consecutive patients underwent pancreatic resection for primary pancreatic lesions that were diagnosed with or suspicious of malignancy at the University of Tokyo Hospital. Of these, 107 patients with pancreatic adenocarcinoma were subjects of the present study, excluding 7 cases with metastatic pancreatic malignancy, 19 cases with neuroendocrine tumor, 3 cases with adenosquamous carcinoma, 24 cases with intraductal papillary mucinous neoplasm and 7 cases with benign tumors in pathological diagnosis. EUS-FNA was indicated for pancreatic lesions, except in patients with complete cystic tumors or patients with pathological malignant diagnosis by other modalities including biopsy through endoscopic retrograde pancreatography. The clinical records of these patients were retrospectively reviewed from a prospectively maintained database. This study was conducted in accordance with the ethical guidelines for clinical studies at the University of Tokyo Hospital (Tokyo, Japan). The current research was approved as project number 2158-5 by the University of Tokyo Research Ethics Committee/Institutional Review Board.

\section{EUS-FNA Procedure}

All EUS procedures were performed using an electronic curved linear array scanning echoendoscope (GF-UCT240-AL5 or GF-UCT260, Olympus Medical Systems, Tokyo, Japan; EG-580UT, Fujifilm Medical., Tokyo, Japan), which was connected to a processor featuring color Doppler function (EU-ME1 or EUS-ME2, Olympus Medical Systems; SU-1, Fujifilm Medical), under moderate sedation with intravenous diazepam (10-20 mg) and pethidine hydrochloride (35-70 mg). The type and size $(19,22$, or 25-gauge) of FNA needle were chosen at the discretion of the endosonographers. The EUS-FNA needles used in this study were from Expect (Boston Scientific Japan, Tokyo, Japan), Echo Tip (Cook Japan, Tokyo, Japan), or EZ shot 2 without side port (Olympus Medical Systems). Complications associated with EUS-FNA were defined as any deviation from the expected clinical course during or after EUS-FNA, and were monitored until surgery (16). Adverse events and their severity associated with EUS-FNA were defined according to the criteria proposed by the American Society for Gastrointestinal Endoscopy (ASGE) workshop (17).

\section{Surgical procedures}

Pancreaticoduodenectomy and distal pancreatectomy were performed for lesions located in the head of the pancreas and the body/tail of the pancreas, respectively. Total pancreatectomy was performed when tumors spread throughout the pancreas. Pancreaticoduodenec-tomy was performed in accordance with standardized Whipple's procedures. The double Roux-en-Y procedure or the Child procedure was used for digestive tract reconstruction. The two-stage pancreatojejunostomy method was performed when the main pancreatic duct was narrow, when the pancreas parenchyma was soft, and/or when patients had severe comorbidities (18). D2 lymph node dissection was principally performed for patients with pancreatic adenocarcinoma. The portal vein and/or superior mesenteric vein were resected with the pancreas and reconstructed when these vessels were involved by tumors. 


\section{Diagnostic sensitivity and specificity of EUS-FNA and Contrast Enhanced-Computed Tomography}

The diagnosis of malignancy by EUS-FNA was defined as follows: cytological or histological diagnosis of 'class or group IV/V' based on EUS-FNA. Radiographic diagnosis was performed by a radiologist (N.O.) in a blinded manner. Namely, for 61 patients, $1 \mathrm{~mm}$-sliced contrast enhanced (CE)-CT was used for the diagnosis without clinical information. MRI was also used, in addition to non-CE-CT for patients with renal dysfunction $(n=3)$ or allergy for iodine contrast agent $(n=2)$. This radiographic diagnosis (blinded CT-based radiographic diagnosis) was categorized into five grades $(I-V)$ comparable to cytological/histological diagnosis:grade I: no malignancy, grade II: images between grade II and III, grade III: suggestive of, but not conclusive for malignancy, grade IV: strongly suggestive of malignancy, and grade V: conclusive for malignancy. The diagnosis of malignancy by blinded CT was defined as being 'gradelV/V'.

\section{Statistical analysis}

Continuous variables were expressed as median values with ranges, and were compared using the Wilcoxon's rank-sum test. Categorical variables were expressed as number (\%), and were compared using Fisher's exact test or the chi-square test, as appropriate. The prognostic effect of EUS-FNA (present vs. absent) for pancreatic adenocarcinoma was assessed using a multivariable Cox proportional hazards model after adjusting potential risk factors with $\mathrm{p}<0.10$ in a univariate Cox model. Hazard ratios (HR) and 95\% confidence intervals $(\mathrm{Cl})$ were calculated for each factor. Continuous variables were categorized by the institutional upper limits: carcinoembryonic antigen (CEA) ( $\geq 5$ vs. $<5 \mathrm{ng} / \mathrm{mL}$ ), carbohydrate antigen 19-9 (CA19-9) ( $\geq 37$ vs. $<37 \mathrm{U} / \mathrm{mL}$ ), duke pancreatic monoclonal antigen type 2 (DUPAN-2) ( $\geq 150$ vs. $<150 \mathrm{U} / \mathrm{mL}$ ), and s-pancreas-1 antigen (Span-1) ( $\geq 30$ vs. $<30 \mathrm{U} / \mathrm{mL}$ ). The cumulative relapse incidences were constructed using a competing risk analysis and compared using the Gray test, (19) where death without recurrence was treated as a competing risk and was not censored.

The McNemar test was applied to assess the statistical significance of the diagnostic abilities between EUS-FNA and blinded CT (20). The trends of sensitivity for diagnosing pancreatic adenocarcinoma with a stepwise increase of tumor size from TS1 $(<2 \mathrm{~cm})$ toward TS3 $(>4 \mathrm{~cm})$ were evaluated using the Cochrane-Armitage trend test (21). A two- sided $p$-value $<0.05$ was considered to indicate statistical significance. All statistical analyses were performed using JMP software (version 11.0.6; SAS Institute Inc., Cary, NC) and EZR (Saitama Medical Center, Jichi Medical University, Saitama, Japan), a graphical user interface for $R$ software (The $R$ Foundation for Statistical Computing, Vienna, Austria) (22).

\section{RESULTS}

\section{Patients'Characteristics}

Of the consecutive 107 patients with pancreatic adenocarcinoma, 52 patients underwent EUS-FNA (EUS-FNA group), and 55 patients did not undergo EUS-FNA (non-EUS-FNA group). The chronological proportions of the both groups are shown after dividing into three subgroups of 36 or 35 patients in each; there were no differences between the three subgroups $(p=0.121)$.

\section{EUS-FNA Outcomes}

All pancreatic lesions were visualized using EUS, resulting in a sensitivity of EUS of $100 \%$. The median total EUS-FNA session number required for each patient was one (range: 1-4) (table 1). The median number of needle passes was five (range: 2-13). A 19gauge, 22-gauge, or 25-gauge needle was used in 6,38, and 20 procedures, respectively. The median duration between EUS-FNA and surgery was 26 days (7-656 days). The complication rate was $5.8 \%$ (3/52): 3 mild pancreatitis which recovered with conservative treatment (17).

Table 1 - Outcomes of the endoscopic ultrasound-guided fine-needle aspiration (EUS-FNA) procedure

\begin{tabular}{|c|c|c|}
\hline Total EUS-FNA session, time & 78 & \\
\hline By patient, time [range] & 1 & [1-4] \\
\hline $\begin{array}{l}\text { Average puncture number in one session } \\
\text { of EUS-FNA, time [range] }\end{array}$ & 5 & [2-8] \\
\hline $\begin{array}{l}\text { Main needle size } \text {, patient } \\
\text { 19-gauge } \\
\text { 22-gauge } \\
\text { 25-gauge }\end{array}$ & $\begin{array}{c}6 \\
38 \\
20\end{array}$ & \\
\hline $\begin{array}{l}\text { Duration from the last EUS-FNA to surgery, } \\
\text { day [range] }\end{array}$ & 26 & {$[7-656]$} \\
\hline Overall complications, n (\%) & 3 & $(5.8)$ \\
\hline Mild pancreatitis & 3 & (5.8) \\
\hline
\end{tabular}

aMultiple punctures were included

Abbriviation; EUS-FNA, endoscopic ultrasound-guided fine-needle aspiration 


\section{Diagnostic sensitivity and specificity of EUS-FNA and Blinded CT}

Sensitivity of EUS-FNA for diagnosing pancreatic adenocarcinoma was $90.4 \%$ (47/52), where as those of the blinded CT-based diagnosis were 69.2\% (36/52) (fig. 1). The diagnostic sensitivity of EUS-FNA was significantly higher than that of blinded CT using the McNemar test $\left(\chi^{2}=4.8, d f=1, p=0.029\right)$. Details of 5 patients with false negative diagnoses by EUS-FNA were summarized in supplementary table 1 . In contrast, CT diagnoses on false negative cases were observed in patients with suspicion of autoimmune pancreatitis $(n=4)$, and invasive adenocarcinoma associated with IPMN $(n=3)$, and small size of tumor $(n=9)$. The sensitivity of EUS-FNA and blinded CT for diagnosing pancreatic malignancy according to tumor size were shown in fig. 2. The sensitivity of blinded CT was significantly associated with increasing tumor size from TS1 to TS3 (Cochran-Armitage trend test, $p=0.016)$, whereas there was no relationship between sensitivity of EUS-FNA and tumor size $(p=0.178)$.

\section{Comparison of Patients'Characteristics}

Patients' characteristics are summarized in table 2. In the non-EUS-FNA group, 13 patients (23.6\%) were diagnosed preoperatively based on biopsy through

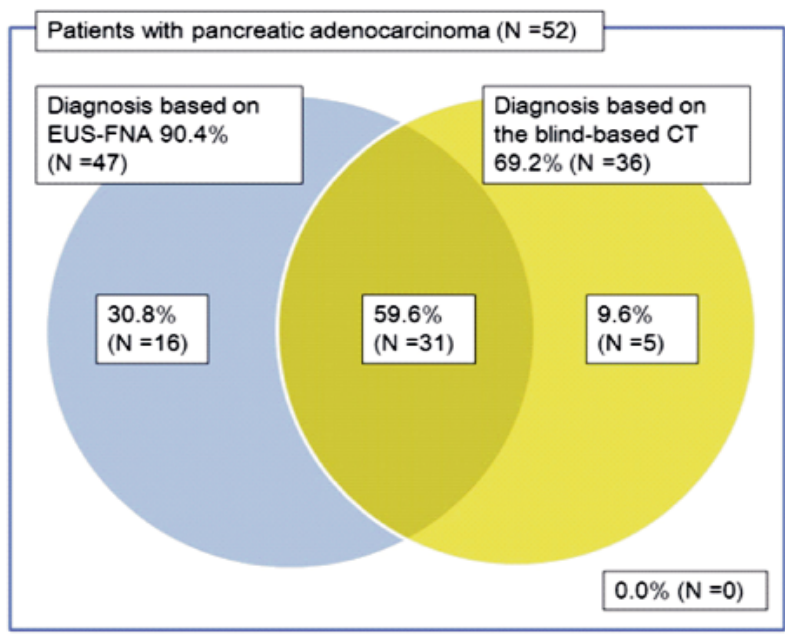

Figure 1 - Diagnostic sensitivity of EUS-FNA and blinded CT for patients with pancreatic malignancy.

EUS-FNA, endoscopic ultrasound-guided fine-needle aspiration; CT, computed tomography.

endoscopic retrograde cholangiography, while the other 42patients (76.4\%) were diagnosed based on radiological studies without pathological examination. There were no differences between the groups in age, men/women ratio, tumor location, American Society of Anesthesiologists score, preoperative biliary drainage, neoadjuvant chemotherapy administration, or tumor markers including CEA, CA19-9, DUPAN-2, and Span-1.

Supplementary Table 1 - Details of patients with difficult preoperative diagnosis

\begin{tabular}{|c|c|c|c|c|c|c|c|c|c|}
\hline Case & $\begin{array}{c}\text { Age } \\
\text { (years) }\end{array}$ & Sex & $\begin{array}{l}\text { Radiological findings } \\
\text { CT Findings }\end{array}$ & $\begin{array}{c}\text { Size } \\
(\mathrm{mm})\end{array}$ & Diagnosis & EUS findings & $\begin{array}{l}\text { EUS-FNA diagnosis } \\
\text { Histology }\end{array}$ & $\begin{array}{l}\text { Cytology } \\
\text { (class) }\end{array}$ & $\begin{array}{l}\text { Pathological diagnosis } \\
\text { of surgical specimen }\end{array}$ \\
\hline 1 & 70 & $\mathrm{M}$ & $\begin{array}{l}\text { Low density lesion } \\
\text { with posterior invasion. }\end{array}$ & 32 & Adenocarcinoma & $\begin{array}{l}\text { Solid mass } \\
\text { with posterior } \\
\text { invasion in the } \\
\text { body of pancreas }\end{array}$ & $\begin{array}{l}\text { Atypical epithelium } \\
\text { of the pancreas }\end{array}$ & 3 & $\begin{array}{l}\text { Moderately differentiated } \\
\text { adenocarcinoma }\end{array}$ \\
\hline 2 & 70 & $\mathrm{~F}$ & $\begin{array}{l}\text { Invasion to the } \\
\text { duodenum and the } \\
\text { stenosis of main } \\
\text { pancreatic duct. }\end{array}$ & 11 & Adenocarcinoma & $\begin{array}{l}\text { Solid mass with } \\
\text { the stenosis of } \\
\text { main pancreatic } \\
\text { duct in the head } \\
\text { of pancreas }\end{array}$ & $\begin{array}{l}\text { Atypical epithelium } \\
\text { of the pancreas }\end{array}$ & 2 & $\begin{array}{l}\text { Well differentiated } \\
\text { adenocarcinoma }\end{array}$ \\
\hline 3 & 86 & $\mathrm{~F}$ & $\begin{array}{l}\text { Stenosis of main } \\
\text { pancreatic duct. }\end{array}$ & 24 & Adenocarcinoma & $\begin{array}{l}\text { Solid mass with } \\
\text { the stenosis of } \\
\text { main pancreatic } \\
\text { duct in the body } \\
\text { of pancreas }\end{array}$ & Normal pancreas & 1 & $\begin{array}{l}\text { Well differentiated } \\
\text { adenocarcinoma }\end{array}$ \\
\hline 4 & 69 & $\mathrm{~F}$ & $\begin{array}{l}\text { Posterior invasion } \\
\text { and adherent to } \\
\text { inferior vena cava. }\end{array}$ & 30 & Adenocarcinoma & $\begin{array}{l}\text { Solid mass with } \\
\text { chronic pancreatitis } \\
\text { in the head/body } \\
\text { of pancreas }\end{array}$ & $\begin{array}{l}\text { Severe fibrous } \\
\text { tissue with inflammation }\end{array}$ & n & $\begin{array}{l}\text { Moderately differentiated } \\
\text { adenocarcinoma }\end{array}$ \\
\hline 5 & 66 & $\mathrm{~F}$ & $\begin{array}{l}\text { Invasion to the } \\
\text { duodenum, and } \\
\text { peripancreatic lymph } \\
\text { node swelling }\end{array}$ & 33 & Adenocarcinoma & $\begin{array}{l}\text { Solid mass with } \\
\text { the stenosis of } \\
\text { main pancreatic duct } \\
\text { in the head of pancreas }\end{array}$ & $\begin{array}{l}\text { Atypical epithelium } \\
\text { of the pancreas } \\
\text { as }\end{array}$ & 3 & $\begin{array}{l}\text { Acinar cell } \\
\text { adenocarcinoma }\end{array}$ \\
\hline
\end{tabular}

Abbreviations: CT, computed tomography; MRI, magnetic resonance imaging; DWI, diffusion weighted image; IPMN, intrapapillary mucinous neoplasm 


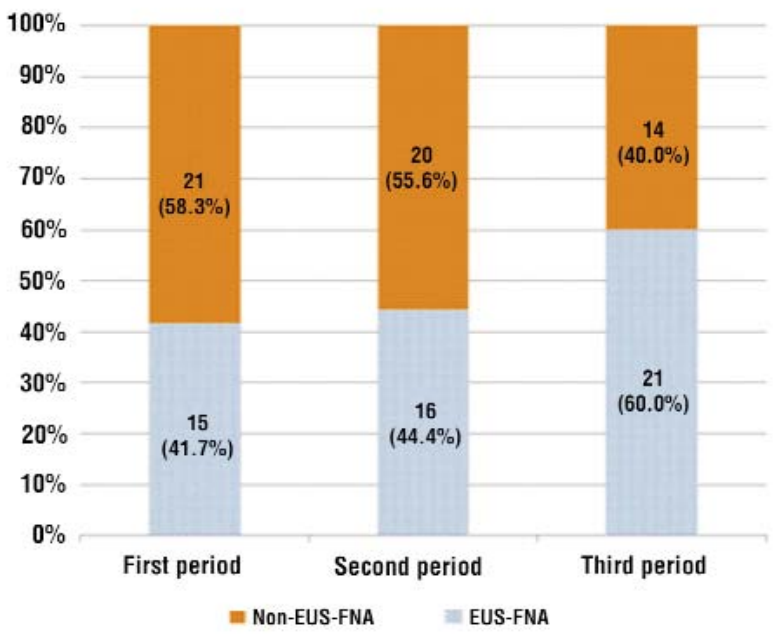

Figure 2 - Sensitivity of EUS-FNA and blinded CT for diagnosing pancreatic malignancy with respect to tumor size EUS-FNA, endoscopic ultrasound-guided fine-needle aspiration; CT, computed tomography.

\section{Intra-operative, post-operative, and histopathological outcomes}

All patients underwent pancreas resection. Intraoperative, post-operative, and histopathological out- comes are summarized in table 3. There were no differences between the groups for operative method, lymph node dissection, resection status, operating time, estimated blood loss, tumor size, International Union Against Cancer (UICC)-TNM classification (version 7), UICC stage, and the rate of adjuvant chemotherapy. The rate of invasive intrapapillary mucinous carcinoma was significantly higher in the non-EUS-FNA group compared with the EUS-FNA group $(p=0.048)$.

\section{Overall Survival}

During the follow-up periods (median: 21.0 months, range: $1.4-37.9$ months). The 12-, 24-, and 36 -month overall survival (OS) rates were $89.1 \%$, $66.3 \%$, and $39.7 \%$, respectively, in the EUS-FNA group, and $87.9 \%, 64.6 \%$, and $55.7 \%$, respectively, in the non-EUS-FNA group (fig. 3a). The 12-, 24-, and 36-month recurrence-free survival (RFS) rates were $75.3 \%, 53.7 \%$, and $41.4 \%$, respectively, in the EUS-FNA group, and $66.9 \%, 55.5 \%$, and $44.4 \%$, respectively, in the non-EUS-FNA group (fig. $3 b$ ). There were no differences in the OS or RFS rates between the two groups $(p=0.958$ and $p=0.357$, respectively).

Table 2 - Patient characteristics

\begin{tabular}{|c|c|c|c|c|c|}
\hline & \multicolumn{2}{|c|}{ EUS-FNA } & \multicolumn{2}{|c|}{ Non-EUS-FNA } & \multirow[t]{2}{*}{$p$ value } \\
\hline Number of patients & & 52 & & 55 & \\
\hline Age, year [range] & 70 & {$[39-86]$} & 70 & {$[42-82]$} & 0.795 \\
\hline Other malignancy history, $\mathrm{n}(\%)$ & 9 & $(17.3)$ & 6 & $(10.9)$ & 0.409 \\
\hline $\begin{array}{l}\text { Sex, } n(\%) \\
\text { Men } \\
\text { Women }\end{array}$ & $\begin{array}{l}36 \\
16\end{array}$ & $\begin{array}{l}(69.2) \\
(30.7)\end{array}$ & $\begin{array}{l}30 \\
25\end{array}$ & $\begin{array}{l}(54.5) \\
(45.4)\end{array}$ & 0.163 \\
\hline ASA score, n (\%) & $\begin{array}{c}5 \\
38 \\
9\end{array}$ & $\begin{array}{l}(9.6) \\
(73.1) \\
(17.3)\end{array}$ & $\begin{array}{c}14 \\
35 \\
6\end{array}$ & $\begin{array}{l}(25.4) \\
(63.6) \\
(10.9)\end{array}$ & 0.086 \\
\hline $\begin{array}{l}\text { Location of pancreatic lesion, } \mathrm{n}(\%) \\
\text { Head } \\
\text { Body } \\
\text { Tail }\end{array}$ & $\begin{array}{c}26 \\
21 \\
5\end{array}$ & $\begin{array}{c}(50.0) \\
(40.4) \\
(9.6)\end{array}$ & $\begin{array}{c}31 \\
17 \\
7\end{array}$ & $\begin{array}{l}(56.3) \\
(30.9) \\
(12.7)\end{array}$ & 0.742 \\
\hline Cystic lesion, $n(\%)$ & 4 & $(7.7)$ & 12 & $(21.8)$ & 0.010 \\
\hline $\begin{array}{l}\text { Tumor markers } \\
\text { CEA, ng/mL [range] } \\
\text { CA19-9, U/mL [range] } \\
\text { DUPAN-2, U/mL [range] } \\
\text { Span- } 1, \mathrm{U} / \mathrm{mL} \text { [range] }\end{array}$ & $\begin{array}{l}4.0 \\
75 \\
62 \\
32\end{array}$ & $\begin{array}{c}{[1.0-25.6]} \\
{[1-3151]} \\
{[25-16000]} \\
{[10-972]}\end{array}$ & $\begin{array}{l}3.8 \\
56 \\
39 \\
34\end{array}$ & $\begin{array}{c}{[0.9-28.0]} \\
{[1-3714]} \\
{[16-3350]} \\
{[10-1589]}\end{array}$ & $\begin{array}{l}0.236 \\
0.812 \\
0.167 \\
0.694\end{array}$ \\
\hline $\begin{array}{l}\text { Preoperative histological diagnosis } \\
\text { except EUS-FNA, } n(\%)\end{array}$ & 0 & $(0.0)$ & 13 & (23.6)a & $<0.001$ \\
\hline Preoperative bile duct drainage, $\mathrm{n}(\%)$ & 11 & $(21.1)$ & 15 & $(27.2)$ & 0.505 \\
\hline NAC administration, $\mathrm{n}(\%)$ & 4 & $(7.7)$ & 3 & $(5.4)$ & 0.834 \\
\hline
\end{tabular}

${ }^{a}$ All 13 patients were diagnosed histologically by endoscopic retrograde cholangiopancreatography.

Abbreviations: EUS-FNA, endoscopic ultrasound-guided fine-needle aspiration; ASA, American Society of Anesthesiologists;

CEA, carcinoembryonic antigen; CA19-9, carbohydrate antigen 19-9; DUPAN-2, duke pancreatic monoclonal antigen type 2;

aSpan-1, s-pancreas-1 antigen; NAC, neoadjuvant chemotherapy 
Table 3 - Intraoperative, postoperative, and histological outcomes

\begin{tabular}{|c|c|c|c|c|c|}
\hline & \multicolumn{2}{|c|}{ EUS-FNA } & \multicolumn{2}{|c|}{ Non-EUS-FNA } & \multirow[t]{2}{*}{$p$ value } \\
\hline Number of patients & 52 & & 55 & & \\
\hline \multicolumn{6}{|l|}{ Intraoperative outcomes } \\
\hline $\begin{array}{l}\text { Operative method, } n(\%) \\
\text { PD } \\
\text { PD with two-staged pancreaticojejunostomy } \\
\text { DP } \\
\text { TP }\end{array}$ & $\begin{array}{c}25 \\
3 \\
23 \\
4\end{array}$ & $\begin{array}{c}(48.1) \\
(5.8) \\
(44.2) \\
(7.7)\end{array}$ & $\begin{array}{c}32 \\
7 \\
22 \\
1\end{array}$ & $\begin{array}{c}(58.1) \\
(12.7) \\
(40.0) \\
(1.8)\end{array}$ & 0.310 \\
\hline $\begin{array}{l}\text { Lymph node dissection, } \mathrm{n}(\%) \\
\text { N0 } \\
\text { N1 } \\
\text { N2 }\end{array}$ & $\begin{array}{l}1 \\
11 \\
40\end{array}$ & $\begin{array}{l}(1.9) \\
(21.1) \\
(76.9)\end{array}$ & $\begin{array}{c}3 \\
12 \\
40\end{array}$ & $\begin{array}{l}0.618 \\
(5.4) \\
(21.8) \\
(72.7)\end{array}$ & \\
\hline Operative time, min [range] & 543 & [227-951] & 496 & {$[151-797]$} & 0.242 \\
\hline Estimated blood loss, $\mathrm{mL}$ [range] & 460 & [90-2710] & 640 & [10-2810] & 0.507 \\
\hline Blood transfusion, $\mathrm{n}(\%)$ & 6 & $(11.5)$ & 7 & $(12.7)$ & $>0.999$ \\
\hline \multicolumn{6}{|l|}{ Histopathological outcomes } \\
\hline $\begin{array}{l}\text { Histological type, } \mathrm{n}(\%) \\
\text { Adenocarcinoma } \\
\text { Invasive IPMC }\end{array}$ & $\begin{array}{c}48 \\
4\end{array}$ & $\begin{array}{c}(92.3) \\
(7.7)\end{array}$ & $\begin{array}{l}44 \\
11\end{array}$ & $\begin{array}{l}(80.0) \\
(20.0)\end{array}$ & $\begin{array}{l}0.429 \\
0.048\end{array}$ \\
\hline $\begin{array}{c}\text { TS, } \mathrm{n}(\%) \\
1 \\
2 \\
3 \\
4\end{array}$ & $\begin{array}{c}11 \\
29 \\
9 \\
3\end{array}$ & $\begin{array}{c}(21.1) \\
(55.7) \\
(17.3) \\
(5.7)\end{array}$ & $\begin{array}{l}10 \\
25 \\
13 \\
7\end{array}$ & $\begin{array}{l}(18.1) \\
(45.4) \\
(23.6) \\
(12.7)\end{array}$ & 0.459 \\
\hline $\begin{array}{l}\text { UICC-T classification, } \mathrm{n} \mathrm{( \% )} \\
\text { Is } \\
1 \\
2 \\
3 \\
4\end{array}$ & $\begin{array}{l}0 \\
2 \\
4 \\
26 \\
20\end{array}$ & $\begin{array}{l}(0.0) \\
(3.8) \\
(7.7) \\
(50.0) \\
(38.5)\end{array}$ & $\begin{array}{l}2 \\
5 \\
6 \\
28 \\
14\end{array}$ & $\begin{array}{l}(3.6) \\
(9.1) \\
(10.9) \\
(50.9) \\
(25.4)\end{array}$ & 0.315 \\
\hline $\begin{array}{c}\text { UICC-N classification, }(\%) \\
0 \\
1\end{array}$ & $\begin{array}{l}22 \\
30\end{array}$ & $\begin{array}{l}(42.3) \\
(57.7)\end{array}$ & $\begin{array}{l}24 \\
31\end{array}$ & $\begin{array}{l}(43.6) \\
(56.4)\end{array}$ & 0.999 \\
\hline $\begin{array}{l}\text { UICC Stage, } \mathrm{n}(\%) \\
0 \\
\text { IA } \\
\text { IB } \\
\text { IIA } \\
\text { IIB } \\
\text { III }\end{array}$ & $\begin{array}{l}0 \\
2 \\
4 \\
13 \\
15 \\
18\end{array}$ & $\begin{array}{l}(0.0) \\
(3.9) \\
(7.7) \\
(25.0) \\
(42.9) \\
(34.7)\end{array}$ & $\begin{array}{l}2 \\
4 \\
2 \\
16 \\
20 \\
11\end{array}$ & $\begin{array}{l}(3.6) \\
(7.3) \\
(3.6) \\
(29.0) \\
(36.3) \\
(20.0)\end{array}$ & 0.551 \\
\hline $\begin{array}{l}\text { Resection status, n (\%) } \\
\text { R0 } \\
\text { R1 } \\
\text { R2 }\end{array}$ & $\begin{array}{c}41 \\
10 \\
1\end{array}$ & $\begin{array}{l}(78.8) \\
(19.2) \\
(1.9)\end{array}$ & $\begin{array}{c}43 \\
11 \\
1\end{array}$ & $\begin{array}{l}(78.1) \\
(20.0) \\
(1.9)\end{array}$ & 0.808 \\
\hline \multicolumn{6}{|l|}{ Postoperative outcomes } \\
\hline $\begin{array}{l}\text { Clavien-Dindo classification, } \mathrm{n}(\%) \\
\text { I } \\
\text { II } \\
\text { III } \\
\text { IV } \\
\text { V }\end{array}$ & $\begin{array}{l}19 \\
29 \\
2 \\
2 \\
0\end{array}$ & $\begin{array}{l}(36.5) \\
(55.8) \\
(3.8) \\
(3.8) \\
(0.0)\end{array}$ & $\begin{array}{l}19 \\
30 \\
5 \\
0 \\
1\end{array}$ & $\begin{array}{l}0.386 \\
(34.5) \\
(54.5) \\
(9.0) \\
(0.0) \\
(1.8)\end{array}$ & \\
\hline Adjuvant chemotherapy, $\mathrm{n}(\%)$ & 36 & $(69.2)$ & 34 & $(61.8)$ & 0.393 \\
\hline
\end{tabular}

Abbreviations: EUS-FNA, endoscopic ultrasound-guided fine-needle aspiration;PD, pancreaticoduodenectomy; DP, distal pancreatectomy; TP, total pancreatectomy; PR, percial resection; IPMC, intrapapillary mucinous carcinoma; TS, tumor size; UICC, International Union Against Cancer

\section{Needle tract seeding after EUS-FNA and local relapse rates}

Tumor cell seeding along the needle track at the gastric wall was suspected in one patient $(1.9 \%)$ based on gastroscopy findings at 12 months after distal pancreatectomy. The cumulative relapse rate at peripancreatic tissue and/or the peritoneum using a competing risks model is shown in fig. 3c. The 12-, 24-, and 36- month relapse rate at peripancreatic tissue and/or the peritoneum were $13.0 \%(95 \% \mathrm{Cl}$ : 5.6-23.7), $17.8 \%$ (95\% Cl: $7.3-32.0)$, and $17.8 \%$ (95\% Cl: $7.3-32.0)$, 

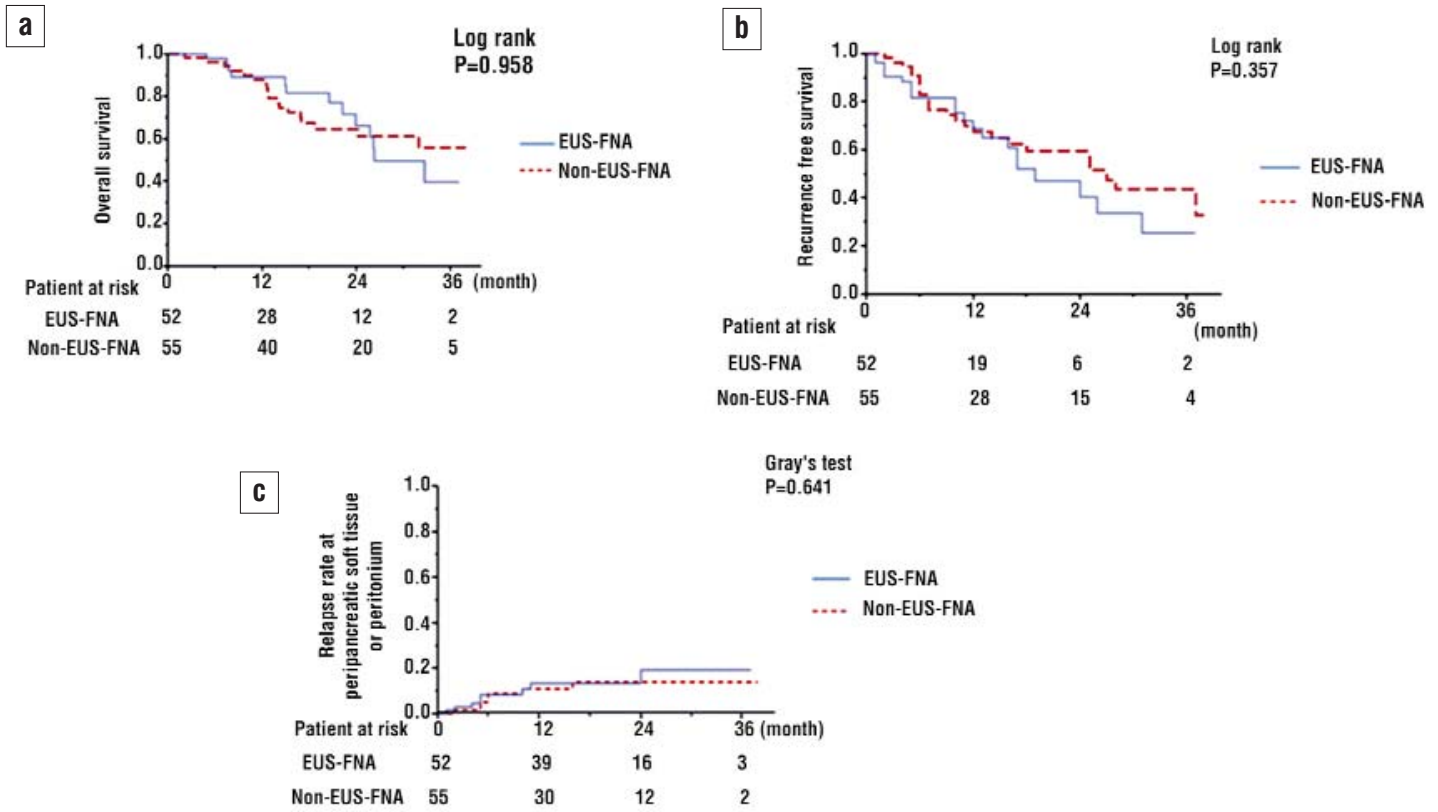

Figure 3 - Overall survival and recurrence free survival between the EUS-FNA group and the non-EUS-FNA group. (a) Overall survival ( $p=0.958$, Log rank test).(b) Recurrence-free survival ( $p=0.357$, Log rank test).(c) Cumulative relapse rate at peripancreatic tissue and/or the peritoneum stratified by the EUS-FNA group and the non-EUS-FNA group ( $p=0.641$, Graytest) EUS-FNA, endoscopic ultrasound-guided fine-needle aspiration;

Supplementary FIG.Proportion of patients who underwent EUS-FNA and those who did not. There were no differences between the three periods $(p=0.121)$

EUS-FNA, endoscopic ultrasound-guided fine-needle aspiration;

respectively, in the EUS-FNA group, and $10.6 \%(95 \% \mathrm{Cl}$ : 4.2-20.3), $12.8 \%$ (95\% Cl: 5.5-23.3), and $12.8 \%$ (95\%Cl: 5.5-23.3), respectively, in the non-EUS-FNA group. There was no difference in the relapse rate at peripancreatic tissue and/or peritoneum between the groups ( $p=0.641$, Gray's test).

\section{Prognostic assessment of EUS-FNA}

A multivariable Cox proportional hazards model (table 4) was applied to evaluate the risk of EUS-FNA for OS and RFS adjusting for other potential risk factors. EUS-FNA was not a significant risk factor for OS (HR: 1.09, 95\% Cl: $0.43-2.63, \mathrm{p}=0.844$ ) or RFS (HR: 1.15 , $95 \% \mathrm{Cl}: 0.56-2.03, \mathrm{p}=0.356)$. In this cohort, there was no significant independent risk factor for OS.A Span-1 $\geq 30$ (HR: 2.12), preoperative biliary drainage (HR: 2.70 ), and $\mathrm{R} 1$ or $\mathrm{R} 2$ resection (HR: 2.23) were independent risk factors for RFS.

\section{DISCUSSION}

Our study demonstrated that the sensitivity of EUS-FNA for diagnosing pancreatic malignancy was significantly better than that of blinded CT. In particular, the diagnostic sensitivity of EUS-FNA for pancreatic malignancy was high irrespective of tumor size, whereas that of blinded CT was influenced by tumor size. Preoperative application of EUS-FNA did not increase the relapse rate at peripancreatic tissue and/or the peritoneum, and was not a risk factor for poor prognosis.

The sensitivity of EUS-FNA in our study (90.4\%) was similar to that previously reported (range of 87-94\%) 5, 23,24 and higher than the sensitivity of blinded CT (69.1\%). EUS-FNA accurately diagnosed pancreatic adenocarcinoma in 16 of 16 (100\%) patients who had false negative diagnoses by radiographic findings. The 16 patients had small size of tumor, autoimmune pancreatitis, and IPMN-related invasive adenocarcinoma (fig. 1). The sensitivity of EUS-FNA for pancreatic adenocarcinoma was approximately $90 \%$ irrespective of tumor size. However, blinded CT tended to be higher with increasing tumor size (fig. 2). Taken together, EUS-FNA is particularly useful for diagnosing small pancreatic malignancy, tumors with pancreatitis, or invasive intraductal papillary mucinous adenocarcinoma. It should be noted that false negative 
Table 4 - Univariate and multivariate Cox proportional-hazards model to identify risk factors for overall survival and recurrence-free survival

\begin{tabular}{|c|c|c|c|c|c|c|}
\hline \multirow[t]{2}{*}{ Variables } & \multicolumn{3}{|c|}{ Univariate analysis } & \multicolumn{3}{|c|}{ Multivariate analysis } \\
\hline & HR & $95 \% \mathrm{Cl}$ & p value & HR & $95 \% \mathrm{CI}$ & $p$ value \\
\hline \multicolumn{7}{|l|}{ Overall survival } \\
\hline \multicolumn{7}{|l|}{ Preoperative factor } \\
\hline Age, $\geq 65 / \leq 65$ & 1.12 & $0.47-3.09$ & 0.802 & & & \\
\hline Sex, men vs. women & 0.56 & $0.25-1.30$ & 0.173 & & & \\
\hline CA19-9, $\geq 37 / \leq 37$ & 1.08 & $0.47-2.81$ & 0.849 & & & \\
\hline $\mathrm{CEA}, \geq 5 / \leq 5$ & 0.72 & $0.28-1.66$ & 0.458 & & & \\
\hline DUPAN-2, $\geq 150 / \leq 150$ & 1.32 & $0.59-2.91$ & 0.483 & & & \\
\hline Supan- $1, \geq 30 / \leq 30$ & 1.22 & $0.54-3.01$ & 0.631 & & & \\
\hline EUS-FNA & 1.10 & $0.49-2.44$ & 0.795 & 1.09 & $0.43-2.63$ & 0.844 \\
\hline Preoperative biliary drainage & 2.66 & $1.14-5.90$ & 0.023 & & & \\
\hline \multicolumn{7}{|l|}{ Surgical factor } \\
\hline Surgical procedure, TP vs. other operation & 5.28 & $1.22-15.8$ & 0.028 & & & \\
\hline Dissection oflymph node, D2 vs. D1 or D0 & 0.83 & $0.27-2.06$ & 0.834 & & & \\
\hline Curative resection, R1 or R2 vs. R0 & 1.94 & $0.79-4.40$ & 0.139 & & & \\
\hline Clavien-Dindo classification, $\geq I I I \mid \leq I I$ & 1.97 & $0.57-5.21$ & 0.251 & & & \\
\hline \multicolumn{7}{|l|}{ Pathological factor } \\
\hline Tumor size, $\geq 4 \mathrm{~cm} / \leq 3.9 \mathrm{~cm}$ & 1.39 & $0.73-2.52$ & 0.291 & & & \\
\hline UICC-T classification, $\geq 3 / \leq 2$ & 1.58 & $0.44-11.9$ & 0.717 & & & \\
\hline UICC-N classification, $\geq 1 / 0$ & 2.11 & $1.15-4.03$ & 0.993 & & & \\
\hline Neoadjuvant chemotherapy & 1.58 & $0.54-3.66$ & 0.606 & & & \\
\hline Adjuvant chemotherapy & 1.28 & $0.19-4.72$ & 0.341 & & & \\
\hline \multicolumn{7}{|l|}{ Recurrence-free survival } \\
\hline \multicolumn{7}{|l|}{ Preoperative factor } \\
\hline Age, $\geq 65 / \leq 65$ & 10.8 & $0.46-1.80$ & 0.727 & & & \\
\hline Sex, men vs. women & 0.77 & $0.40-1.52$ & 0.445 & & & \\
\hline$C A 19-9, \geq 37 / \leq 37$ & 1.67 & $0.84-3.60$ & 0.360 & & & \\
\hline $\mathrm{CEA}, \geq 5 / \leq 5$ & 1.20 & $0.28-1.66$ & 0.458 & & & \\
\hline DUPAN- $2, \geq 150 / \leq 150$ & 1.32 & $0.63-2.24$ & 0.561 & & & \\
\hline Span- $1, \geq 30 / \leq 30$ & 2.50 & $1.26-5.41$ & $<0.001$ & 2.12 & $1.03-4.72$ & 0.039 \\
\hline EUS-FNA & 1.34 & $0.72-2.51$ & 0.340 & 1.15 & $0.56-2.03$ & 0.356 \\
\hline Preoperative biliary drainage & 2.93 & $1.48-5.61$ & 0.002 & 2.70 & $1.27-5.67$ & 0.010 \\
\hline \multicolumn{7}{|l|}{ Surgical factor } \\
\hline Surgical procedure, TP vs. other operation & 5.01 & $1.17-14.7$ & 0.032 & & & \\
\hline Dissection oflymph node, D2 vs. D1 or D0 & 0.72 & $0.37-1.83$ & 0.834 & & & \\
\hline Curative resection, R1 or R2 vs. R0 & 2.52 & $1.25-4.80$ & 0.010 & 2.23 & $1.06-4.74$ & 0.019 \\
\hline Clavien-Dindo classification, $\geq I I I \mid \leq I I$ & 1.87 & $0.48-4.21$ & 0.562 & & & \\
\hline \multicolumn{7}{|l|}{ Pathological factor } \\
\hline Tumor size, $\geq 4 \mathrm{~cm} / \leq 3.9 \mathrm{~cm}$ & 1.57 & $0.78-2.33$ & 0.190 & & & \\
\hline UICC-T classification, $\geq 3 / \leq 2$ & 1.77 & $0.70-5.93$ & 0.241 & & & \\
\hline UICC-N classification, $\geq 1 / 0$ & 1.26 & $0.67-2.47$ & 0.478 & & & \\
\hline Neoadjuvant chemotherapy & 1.23 & $0.36-3.08$ & 0.701 & & & \\
\hline Adjuvant chemotherapy & 1.16 & $0.38-3.62$ & 0.156 & & & \\
\hline
\end{tabular}

Abbreviations: CEA, carcinoembryonic antigen; CA19-9, carbohydrate antigen 19-9; DUPAN-2, duke pancreatic monoclonal antigen type 2; Span-1, s-pancreas-1 antigen; EUS-FNA, endoscopic ultrasound-guided fine-needle aspiration; TP, total pancreatectomy; UICC, International Union Against Cancer. 
diagnoses by EUS-FNA were observed in 5 patients although the reason was unclear. The diagnostic accuracy of EUS-FNA was also significantly better than that of blinded CT $(p=0.021)$. Overall, all patients $(100 \%, 52 / 52)$ were accurately diagnosed preoperatively based on the combination of EUS-FNA and blinded CT.

EUS-FNA is a well-established technique for diagnosis of pancreatic lesions with acceptable complication rates $(25,26)$. In our series, three of 52 patients (5.8\%) developed minor complications and recovered with conservative treatment within a few days. Thus, EUS-FNA is unlikely to prolong the period to operation. However, some surgeons do not prefer preoperative EUS-FNA, due to concerns of tumor cell seeding along the needle track or at the peritoneum. Indeed, there are previous reports of tumor seeding at the gastric wall due to the needle track (9-15). In our study, the relapse rates at peripancreatic tissue and/or the peritoneum were similar between the EUS-FNA (36-month: 17.8\%) and the non-EUS-FNA (36-month: $12.8 \% ; \mathrm{p}=0.641$ ) groups after adjusting for competing death events, although one patient $(1.9 \%)$ likely developed needle track seeding at the gastric wall. Conversely, Ngamruengphong et al. reported a similar rate of local or peritoneal recurrence for patients receiving EUS-FNA (7.7\%) compared with those who did not (15.7\%; $\mathrm{p}=0.21)(27)$.

A multivariate Cox proportional hazards model revealed that EUS-FNA was not a significant risk factor for OS after adjusting for other potential risk factors. Ngamruengphong et al. examined 2034 patients with pancreatic cancer, including 498 patients who underwent EUS-FNA (28). In that study, the use of EUS-FNA was associated with marginally improved OS (HR: 0.84, 95\% Cl: 0.72-0.99) and with cancer-specific survival (HR: $0.87,95 \% \mathrm{Cl}: 0.74-1.03$ ) in multivariable analysis, after controlling for several variables. The authors suggest that the better outcomes in patients receiving EUS-FNA were due to improvement of stageappropriate management, selection for curative intent surgery, and perioperative adjuvant chemotherapy and/or radiotherapy. Importantly, the study included patients over a long period (1998-2009), and likely had ahistorical bias as patients did not undergo EUS-FNA and/or perioperative adjuvant chemotherapy and/or radiotherapy in the early 2000s. In a retrospective evaluation of 54 patients who underwent EUS-FNA and 28 patients who did not, Kudo et al. reported a significant improvement in RFS and OS in EUS-FNA patients, although the reason for improved prognosis was not discussed (29). Our study included patients who underwent surgery within the last 3 years with a relatively similar chronological proportion of EUS-FNA, and demonstrated that EUS-FNA was not associated with poor OS or RFS.

The main limitations of our study are the retrospective design, the small number of patients, and the relatively short follow-up period. Additionally, patients who did not undergo surgical resection should be included to examine the diagnostic accuracy of EUSFNA and radiographic studies, although this evaluation was not accurately conducted owing to the lack of pathological diagnosis based on surgical specimens. Further analyses with a large number of patients in a well-designed multicenter study are needed to evaluate the advantage/disadvantage of routine use of EUS-FNA for patients with resectable pancreatic adenocarcinoma.

\section{CONCLUSION}

In conclusion, EUS-FNA is particularly useful for diagnosing small pancreatic adenocarcinoma, tumors with pancreatitis, or invasive intraductal papillary mucinous adenocarcinoma which hinders diagnosis based on radiographic images. EUS-FNA isa safe modality for resectable pancreatic adenocarcinoma with high diagnostic sensitivity and acceptable prognostic outcomes.

Financial Disclosure: None.

Funding/Support: None.

\section{Conflicts of interest}

The authors declare that no competing interests exist.

\section{REFERENCES}

1. Vincent A, Herman J, Schulick R, Hruban RH, Goggins M. Pancreatic cancer. Lancet. 2011 Aug 13;378(9791):607-20.

2. Ryan DP, Hong TS, Bardeesy N. Pancreatic adenocarcinoma. N Engl J Med. 2014;371:1039-49.

3. Raimondi S, Maisonneuve $P$, Lowenfels $A B$. Epidemiology of pancreatic cancer: an overview. Nat Rev Gastroenterol Hepatol. 2009;6:699-708.

4. Vilmann P, Jacobsen GK, Henriksen FW, Hancke S. Endoscopic ultrasonography with guided fine needle aspiration biopsy in pancreatic disease. Gastrointest Endosc. 1992;38(2):172-3.

5. Chen J, Yang R, Lu Y, Xia Y, Zhou H. Diagnostic accuracy of endoscopic ultrasound-guided fine-needle aspiration for solid pancreatic lesion: a systematic review. J Cancer Res Clin Oncol. 2012;138(9): 1433-41.

6. Varadarajulu S, Eloubeidi MA. Frequency and significance of acute intracystic hemorrhage during EUS-FNA of cystic lesions of the 
pancreas. Gastrointest Endosc. 2004;60(4):631-5.

7. Das A, Sivak MV Jr, Chak A. Cervical esophageal perforation during EUS: a national survey. Gastrointest Endosc. 2001;53(6):599-602.

8. Adler DG, Jacobson BC, Davila RE, Hirota WK, Leighton JA, Qureshi WA, et al. ASGE guideline: complications of EUS. Gastrointest Endosc. 2005;61(1):8-12.

9. Ahmed K, Sussman JJ, Wang J, Schmulewitz N. A case of EUSguided FNA-related pancreatic cancer metastasis to the stomach. Gastrointest Endosc. 2011;74(1):231-3.

10. Chong A, Venugopal K, Segarajasingam D, Lisewski D. Tumor seeding after EUS-guided FNA of pancreatic tail neoplasia. Gastrointest Endosc. 2011;74(4):933-5.

11. Gress F, Michael H, Gelrud D, Patel P, Gottlieb K, Singh F, et al. EUS-guided fine-needle aspiration of the pancreas: evaluation of pancreatitis as a complication. Gastrointest Endosc. 2002;56(6): 864-7.

12. Hirooka $\mathrm{Y}$, Goto $\mathrm{H}$, Itoh $\mathrm{A}$, Hashimoto $\mathrm{S}$, Niwa $\mathrm{K}$, Ishikawa $\mathrm{H}$, et al. Case of intraductal papillary mucinous tumor in which endosonography-guided fine-needle aspiration biopsy caused dissemination. J Gastroenterol Hepatol. 2003;18(11): 1323-4.

13. Katanuma A, Maguchi H, Hashigo S, Kaneko M, Kin T, Yane K, et al. Tumor seeding after endoscopic ultrasound-guided fine-needle aspiration of cancer in the body of the pancreas. Endoscopy. 2012; 44 Suppl 2 UCTN:E160-1.

14. Paquin SC1, Gariépy G, Lepanto L, Bourdages R, Raymond G, Sahai AV. A first report of tumor seeding because of EUS-guided FNA of a pancreatic adenocarcinoma. Gastrointest Endosc. 2005;61(4):610-1.

15. Shah JN1, Fraker D, Guerry D, Feldman M, Kochman ML. Melanoma seeding of an EUS-guided fine needle track. Gastrointest Endosc. 2004:59(7):923-4.

16. Bhatia V, Varadarajulu S. Endoscopic ultrasonography-guided tissue acquisition: How to achieve excellence. Dig Endosc. 2017; 29(4):417-430.

17. Cotton PB, Eisen GM, Aabakken L, Baron TH, Hutter MM, Jacobson $\mathrm{BC}, \mathrm{t}$ al. A lexicon for endoscopic adverse events: report of an ASGE workshop. Gastrointest Endosc. 2010;71(3):446-54.

18. Hasegawa K, Kokudo N, Sano K, Seyama Y, Aoki T, Ikeda M, et al. Two-stage pancreatojejunostomy in pancreaticoduodenectomy: a retrospective analysis of short-term results. Am J Surg. 2008; 196(1):3-10

19. Espeland MA, Murphy WC, Leverett DH. Assessing diagnostic reliability and estimating incidence rates associated with a strictly progressive disease: dental caries. Stat Med. 1988;7(3):403-16.

20. Mc NQ. Note on the sampling error of the difference between correlated proportions or percentages. Psychometrika. 1947;12(2): 153-7.

21. Bansal S, Buring JE, Rifai N, Mora S, Sacks FM, Ridker PM. Fasting compared with nonfasting triglycerides and risk of cardiovascular events in women. JAMA. 2007;298(3):309-16.

22. Kanda $Y$. Investigation of the freely available easy-to-use software 'EZR' for medical statistics. Bone Marrow Transplant. 2013;48(3): 452-8.

23. Puli SR, Bechtold ML, Buxbaum JL, Eloubeidi MA. How good is endoscopic ultrasound-guided fine-needle aspiration in diagnosing the correct etiology for a solid pancreatic mass?: A meta-analysis and systematic review. Pancreas. 2013;42(1):20-6.

24. Haba S, Yamao K, Bhatia V, Mizuno N, Hara K, Hijioka S, et al. Diagnostic ability and factors affecting accuracy of endoscopic ultrasound-guided fine needle aspiration for pancreatic solid lesions: Japanese large single center experience. J Gastroenterol. 2013; 48(8):973-81.

25. Hamada T, Yasunaga $H$, Nakai $Y$, Isayama $H$, Horiguchi $H$, Matsuda $\mathrm{S}$, et al. Severe bleeding and perforation are rare complications of endoscopic ultrasound-guided fine needle aspiration for pancreatic masses: an analysis of 3,090 patients from 212 hospitals. Gut Liver. 2014;8(2):215-8.

26. Katanuma A, Maguchi H, Yane K, Hashigo S, Kin T, Kaneko M, et al. Factors predictive of adverse events associated with endoscopic ultrasound-guided fine needle aspiration of pancreatic solid lesions. Dig Dis Sci. 2013;58(7):2093-9.

27. Ngamruengphong $\mathrm{S}, \mathrm{Xu} \mathrm{C}$, Woodward TA, Raimondo M, Stauffer $\mathrm{JA}$, Asbun HJ, et al. Risk of gastric or peritoneal recurrence, and long-term outcomes, following pancreatic cancer resection with preoperative endosonographically guided fine needle aspiration. Endoscopy. 2013;45(8):619-26.

28. Ngamruengphong S, Swanson KM, Shah ND, Wallace MB. Preoperative endoscopic ultrasound-guided fine needle aspiration does not impair survival of patients with resected pancreatic cancer. Gut. 2015;64(7):1105-10.

29. Kudo T, Kawakami H, Kuwatani M, Eto K, Kawahata S, Abe Y, et al. Influence of the safety and diagnostic accuracy of preoperative endoscopic ultrasound-guided fine-needle aspiration for resectable pancreatic cancer on clinical performance. World J Gastroenterol. 2014;20(13):3620-7. 